\title{
Erratum
}

\section{Selective N-Benzylation of Amino Acids under Homogeneously Catalyzed Hydrogenation Conditions}

Vitali I. Tararov,* Renat Kadyrov, Christine Fischer, Armin Börner Synlett, 2004, 1961.

The structure of serine (Ser) in Scheme 1 was incorrectly drawn as homoserine. The correct Scheme 1 is:

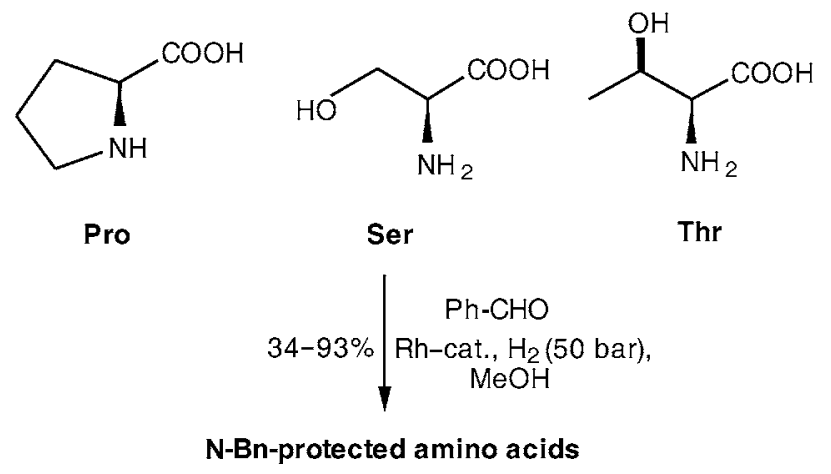

The authors apologize for this error. 